\title{
Parametric evaluation of the Euler-Lagrangian approach for tracer studies
}

\author{
I.T. Tenebe*, A.S. Ogbiye, D.O. Omole, P.C. Emenike \\ Department of Civil Engineering, Covenant University, Ota, Ogun State, Nigeria, emails: yoshearer@gmail.com, \\ imokhai.tenebe@covenantuniversity.edu.ng (I.T. Tenebe), ade.ogbiye@covenantuniversity.edu.ng (A.S. Ogbiye), \\ david.omole@covenatuniversity.edu.ng(D.O.Omole), praisegod.emenike@covenantuniversity.edu.ng (P.C. Emenike)
}

Received 13 October 2017; Accepted 8 March 2018

\section{A B S T R A C T}

The determination of dispersion number or its coefficient is pertinent to the control of pollution. This study evaluated the importance of the parameters measured from a river in South West Nigeria, during tracer studies using the Euler-Lagrangian approach. Several measurements which included tracer concentration, width, velocity, sampling time, and sampling point interval were obtained between January and April of 2017, cutting across the raining and dry seasons for model development and sensitivity analysis. The result revealed that a $1 \%$ increase in the dispersion coefficient will result from a $2.487 \%$ increase in velocity $(t=2.671, p=0.020)$ and $8.914 \%$ increase in the channel width $(t=6.124$, $p=0.000$ ), which were statistically significant at $5 \%$ and $1 \%$, respectively. This finding is well supported by previous studies which made use of the variable distance and constant time method. Furthermore, sampling time $(t=5.087, p=0.000)$, sampling point interval $(t=6.124, p=0.000)$, and tracer concentration $(t=2.453, p=0.030)$ were new variables identified and all were statistically significant and had a direct relationship with dispersion coefficient. It is recommended that the Euler-Lagrangian approach should be adopted in other rivers to verify these claims, as it could be seen as a sustainable method for conducting tracer studies.

Keywords: Dispersion; Dispersion coefficient; Tracer studies; Pollution; Risk assessment; Sustainable methods

${ }^{*}$ Corresponding author. 